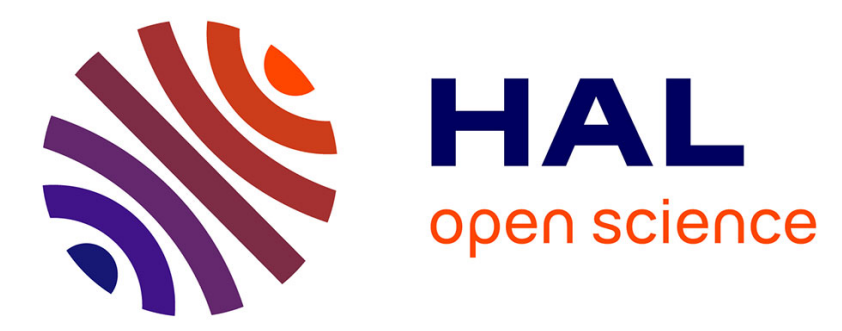

\title{
Characterisation of experimental infections of domestic pigs with genotype 2.1 and 3.3 isolates of classical swine fever virus.
}

H. Everett, F.J. Salguero, S.P. Graham, F. Haines, H. Johns, D. Clifford, A. Nunez, A. La Rocca, S. Parchariyanon, F. Steinbach, et al.

\section{To cite this version:}

H. Everett, F.J. Salguero, S.P. Graham, F. Haines, H. Johns, et al.. Characterisation of experimental infections of domestic pigs with genotype 2.1 and 3.3 isolates of classical swine fever virus.. Veterinary Microbiology, 2010, 142 (1-2), pp.26. 10.1016/j.vetmic.2009.09.039 . hal-00578397

\section{HAL Id: hal-00578397 https://hal.science/hal-00578397}

Submitted on 20 Mar 2011

HAL is a multi-disciplinary open access archive for the deposit and dissemination of scientific research documents, whether they are published or not. The documents may come from teaching and research institutions in France or abroad, or from public or private research centers.
L'archive ouverte pluridisciplinaire HAL, est destinée au dépôt et à la diffusion de documents scientifiques de niveau recherche, publiés ou non, émanant des établissements d'enseignement et de recherche français ou étrangers, des laboratoires publics ou privés. 


\section{Accepted Manuscript}

Title: Characterisation of experimental infections of domestic pigs with genotype 2.1 and 3.3 isolates of classical swine fever virus.

Authors: H. Everett, F.J. Salguero, S.P. Graham, F. Haines, H. Johns, D. Clifford, A. Nunez, A. La Rocca, S. Parchariyanon,

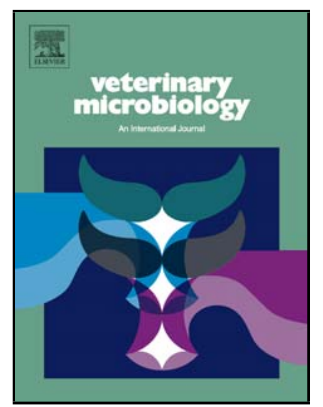
F. Steinbach, T. Drew, H. Crooke

PII:

DOI: S0378-1135(09)00456-8

Reference: $\quad$ VETMIC 4596

To appear in: $\quad$ VETMIC

Please cite this article as: Everett, H., Salguero, F.J., Graham, S.P., Haines, F., Johns, H., Clifford, D., Nunez, A., La Rocca, A., Parchariyanon, S., Steinbach, F., Drew, T., Crooke, H., Characterisation of experimental infections of domestic pigs with genotype 2.1 and 3.3 isolates of classical swine fever virus., Veterinary Microbiology (2008), doi:10.1016/j.vetmic.2009.09.039

This is a PDF file of an unedited manuscript that has been accepted for publication. As a service to our customers we are providing this early version of the manuscript. The manuscript will undergo copyediting, typesetting, and review of the resulting proof before it is published in its final form. Please note that during the production process errors may be discovered which could affect the content, and all legal disclaimers that apply to the journal pertain. 
1 Characterisation of experimental infections of domestic pigs with

2 genotype 2.1 and 3.3 isolates of classical swine fever virus.

3

4 H. Everett ${ }^{1}$, F.J. Salguero ${ }^{1}$, S.P. Graham ${ }^{1}$, F. Haines ${ }^{1}$, H. Johns ${ }^{1}$, D. Clifford ${ }^{1}$,

5 A. Nunez ${ }^{1}$, A. La Rocca ${ }^{1}$, S. Parchariyanon ${ }^{2}$, F. Steinbach ${ }^{1}$, T. Drew ${ }^{1}$ and H.

6 Crooke $^{1 *}$

7

$8{ }^{1}$ Veterinary Laboratories Agency, New Haw, Surrey, KT15 3NB, UK

$9 \quad 2$ The Department of Livestock Development, Bangkok, 10400, Thailand

10 *corresponding author: $\underline{\text { H.crooke@vla.defra.gsi.gov.uk, }}$

11 Tel + $44(0) 1932357331$

$12 \quad$ Fax $+44(0) 1932357239$

13

14 Abstract

15 The early identification of classical swine fever epizootics is hampered by

16 difficulties in recognising early signs of infection, due to a lack of specific

17 clinical signs. In addition many textbook descriptions of CSF are based on

18 observations of disease caused by historic, mainly genotype 1 , strains. Our

19 objective was to improve our knowledge of the diverse range of signs that

20 different CSFV strains can cause by characterising the experimental infection

21 of domestic pigs with both a recent strain of CSFV and a divergent strain.

22 Conventional pigs were inoculated with a genotype 2.1 isolate, that caused an

23 outbreak in the UK in 2000 , and a genotype 3.3 strain that is genetically

24 divergent from European strains. This latter strain is also antigenically distinct

25 as it is only poorly recognised by the CSFV-specific monoclonal antibody, 
1 WH303. Transmission was monitored by use of in-contact animals. Clinical,

2 virological and haematological parameters were observed and an extended

3 macro and histopathological scoring system allowed detailed characterisation

4 of pathological lesions. Infection with the genotype 2.1 isolate resulted in a

5 similar outcome to other recent genotype 2 European strains, whereas the

6 genotype 3.3 strain produced fewer and delayed clinical signs, notably with

7 little fever. This strain would therefore be particularly difficult to detect in the

8 early stages of infection and highlights the importance of encouraging early

9 submission of samples for laboratory diagnosis. As representatives of recent

10 and divergent CSFV isolates, these strains are good candidates to study the

11 pathogenesis of current CSFV isolates and as challenge models for vaccine

12 development.

13

14

15 Keywords: Classical swine fever, genotypes 2.1 and 3.3, experimental 16 infection

\section{Introduction}

Although many areas of the world have eradicated classical swine fever (CSF), epizootics in disease-free regions occur regularly and cause considerable financial and sociological impact. The last outbreak in the UK, in 2000 , resulted in the destruction of over 73,000 animals. Of these, 31,900 were culled pre-emptively as dangerous contacts, or due to their close proximity to confirmed cases, but were subsequently confirmed as not 
1 infected (Paton, 2002). Early detection is key to ensuring that control

2 measures will minimise the spread and the impact of such devastating

3 diseases (Murray and McCutcheon, 1999). Identification of CSFV as the

4 etiological agent of some recent outbreaks has taken two months or more

5 after the virus was introduced. For the UK 2000 outbreak, it is estimated that

6 the virus initially entered the index farm in early June, but confirmation of

7 disease did not occur until August (Gibbens et al., 2000). A lack of

8 pathognomonic signs linked to CSF is one of the factors contributing to delays

9 in its recognition and it has been speculated that recent isolates, for which

10 clinical diagnosis on infected farms was difficult, are of lower virulence

11 (Terpstra and de Smit, 2000). Indeed, European isolates from the late 1990's

12 produced less pronounced and delayed signs in experimental inoculations

13 compared to the historical reference strain, Alfort (Floegel-Niesmann et al., 14 2003).

15 The UK 2000 outbreak was caused by a genotype 2.1 CSFV, which is 16 genetically distinct from previous European 2.1 isolates (Sandvik et al., 2000).

17 The origin of this incursion could not be determined. However, it is thought 18 that exposure of outdoor pigs to an illegally imported infected pork product 19 was the most likely source (Gibbens et al., 2000). Other recent outbreaks, that 20 have been caused by genotype 2.1 strains, such as in the Netherlands in 211997 (Greiser-Wilke et al., 2000) and in South Africa in 2005 (Sandvik et al., 22 2005), highlight that this genotype poses a continued threat to CSF-free 23 countries.

24 Viruses belonging to genotype 3 have had a more restricted distribution, being 25 predominately constrained to the Far East. Isolates of the sub-genotype 3.3 
1 have, thus far, only been collected from Thailand. The nucleotide sequences

2 of characterised 3.3 isolates are quite divergent, indicating that this sub-

3 genotype may have evolved locally for some time (Parchariyanon et al.,

4 2000). This genetic diversity is also reflected by antigenic heterogeneity: 21

5 isolates were classified into 7 different antigenic groups based on monoclonal

6 antibody typing. In particular two isolates, CBR/93 and CBR/94/2, did not

7 react with $\mathrm{Mab}$ WH303 that, to our knowledge, has previously reacted with all

8 other CSFV strains tested (Parchariyanon et al., 2001). This antibody is widely

9 used in differential diagnosis of pestiviruses as it binds an epitope in the E2

10 glycoprotein, TAVSPTTLR, which is conserved in CSFV but not in BVDV and

11 BDV strains (Lin et al., 2000). The TAVSPTTLR epitope is a virulence

12 determinant, as mutants with amino acid substitutions in this region produce

13 mild clinical signs (Risatti et al., 2006), raising the possibility that viruses like

14 CRB/93 or CBR/94/2 would be particularly difficult to detect.

15 This study aimed to characterise the clinical, virological, haematological and

16 pathological features associated with infection of pigs with the UK2000/7.1

17 and $\mathrm{CBR} / 93$ isolates. The results add to the knowledge of the behaviour of

18 modern and diverse strains of CSFV in vivo and establish a challenge model

19 for future vaccination experiments. We have also used a modified pathological

20 scoring system to aid the comparison of experimental infections with different

21 strains of CSFV.

\section{Materials and methods}

25 Viruses 
1 CSFV strain UK2000/7.1 (Sandvik et al., 2000) was isolated from a domestic

2 pig during the UK2000 outbreak and passaged three times in cell culture.

3 CBR/93 was isolated in Thailand in 1993 (Parchariyanon et al., 2000). Viruses

4 were propagated in PK-15 cells as previously described (Drew, 2008). The E2

5 region of the CBR/93 strain was amplified by PCR using SuperScript III

6 Reverse Transcriptase (Invitrogen) and KOD Hot start DNA polymerase

7 (Novagen) and the nucleotide sequence determined by $A B I$ sequencing.

9 Animals

10 Ten-week-old Large White/Landrace cross-breed pigs were obtained from a

11 local commercial supplier. The pigs were clinically healthy and free of 12 antibodies against pestiviruses. All procedures were conducted in accordance 13 with the UK Animals (Scientific Procedures) Act 1986. During the 14 acclimatisation period, biothermal microchips (Destron Technologies Inc.) 15 were implanted subcutaneously behind the left ear for temperature monitoring.

16 Biochip and rectal temperatures taken at the start of the experiment indicated 17 that biochip temperatures were approximately $1^{\circ} \mathrm{C}$ lower than rectal 18 temperatures. Throughout the duration of the study, temperatures and clinical 19 signs were recorded twice daily, using a slightly modified version of a scheme 20 described previously (Mittelholzer et al., 2000). The ten parameters, which 21 were scored between 0 and 3 , were the same as described except a 22 parameter measuring the leftovers at feed was replaced by a clinical score $23(\mathrm{CS})$ for the biochip temperature $\left(37.0^{\circ} \mathrm{C}-38.9^{\circ} \mathrm{C}=\mathrm{CS} 0,39.0^{\circ} \mathrm{C}-39.9^{\circ} \mathrm{C}=\right.$ $24 \mathrm{CS} 1,40.0^{\circ} \mathrm{C}-40.9^{\circ} \mathrm{C}=\mathrm{CS}$ of $2,41.0^{\circ} \mathrm{C}$ or above $\mathrm{CS}=3$ ) 
1

2 For each experiment, six pigs were inoculated by intranasal administration of

$32 \mathrm{ml}$ of CSFV tissue culture supernatant ( $1 \mathrm{ml}$ in each nostril), using a MAD300

4 nasal drug aerosol delivery device (Wolfe Tory Medical Inc.). Back titration of

5 inocula on PK-15 cells verified that $10^{5.6} \mathrm{TCID}_{50}$ of both strains was delivered.

6 After 24h, the inoculated pigs were re-introduced to three in-contact animals in

7 another pen. For each experiment, two uninfected control animals were

8 housed in a separate pen. EDTA blood samples were obtained prior to

9 inoculation and then at 2 to 3 day intervals post infection. Nasal swabs were

10 collected daily. Control animals were sampled at the same time points as

11 inoculated animals. Any animal, with a clinical score above or approaching 15,

12 was euthanized by administration of $20 \%$ Pentobarbitol solution, for humane

13 reasons.

14

15

16

17

18

19

20

21

22

24

25

Viral RNA quantification in nasal swabs and EDTA blood

Nasal swabs were soaked in $1 \mathrm{ml}$ PBS, agitated and then centrifuged at 1500rpm for 7min. Blood samples were collected in EDTA vacutainers (BD

Biosciences). Viral RNA was extracted from $140 \mu$ l nasal swab suspension or EDTA blood using QIAamp 96 DNA Swab BioRobot or QIAamp Viral RNA mini kits (Qiagen), respectively. Viral RNA was quantified using a qRT-PCR one-step Superscript III Platinum kit (Invitrogen). The reaction mix contained $3 \mu \mathrm{l}$ nucleic acid extract, $12.5 \mu \mathrm{l} 2 \mathrm{x}$ reaction mix, a final concentration of $5 \mathrm{mM}$ $\mathrm{MgSO}_{4}, \quad 0.2 \mu \mathrm{l}$ RNAsin, 50nM ROX and $1 \mathrm{U}$ Superscript III reverse transcriptase/Platinum Taq mix. Primers CSF100F and CSF192-R (Hoffmann et al., 2005) were used at a concentration of 600nM and the probe CSF- 
1 Probe-1, which was modified with BHQ1 quencher, was used at 200nM. The

2 viral genome copy number was determined by comparison to a ten-fold serial

3 dilution of a standard included in each PCR. This PCR standard consisted of

4 RNA transcribed in vitro (Megashortscript kit, Ambion) from plasmid

5 pCRXLV324-6 which contains the region of the 5'UTR of CSFV strain Alfort

6 187, flanked by primers V324 and V326 (Vilcek et al., 1994).

7

8 Haematology

9 To monitor thrombocytopenia, EDTA blood $(500 \mu \mathrm{l})$ was centrifuged at $300 \mathrm{~g}$

10 for $1 \mathrm{~min}$ and $5 \mu \mathrm{l}$ plasma were added to $2.5 \mathrm{ml}$ MACSQuant Running Buffer

11 (Miltenyi Biotec). Platelets present in $50 \mu \mathrm{l}$ of this suspension were identified

12 based on forward and side scatter characteristics using a MACSQuant flow

13 cytometer (Miltenyi Biotec). Leukocytes present within $50 \mu$ l of EDTA blood

14 were detected by staining with $10 \mu \mathrm{l}$ of a porcine pan-leukocyte anti-CD45-

15 FITC antibody (AbD Serotec). Samples were then mixed with $940 \mu$ I FACS

16 lysing solution (BD Biosciences), to ensure lysis of erythrocytes and fixation of

17 cells, prior to assessment of total leukocyte counts in $50 \mu$ l of the cell

18 suspension using a MACSQuant flow cytometer.

20 Pathology

21 Post mortem examinations followed standard operational procedures and any

22 observed lesions were recorded. A macropathology scoring system was

23 established (Table I) using a total of 21 parameters. Each parameter was

24 evaluated from 0 (no lesion) to 3 (severe lesion). Samples were fixed in

25 buffered formalin and embedded in paraffin wax. Sections $(4 \mu \mathrm{m})$ were stained 
1 with H\&E for histopathological examination. A histopathological scoring

2 system was also developed using 33 parameters (Table II) and the severity of

3 lesions was also recorded from 0 (no lesion) to 3 (severe). Data from both

4 scoring systems were analyzed by Kruskal-Wallis non-parametric mean

5 comparison test and differences were considered significant for $P<0.05$.

6

7

8

9

\section{Results}

Characterisation of CSFV CBR/93

To confirm that the CBR/93 isolate is variant at the WH303 epitope, PK-15 cells infected with CSFV strain UK2000/7.1 or CBR/93 were stained and analysed by flow cytometry. Whereas UK2000/7.1 was easily detected with Mab WH303 staining of strain CBR/93 was impaired (data not shown). Sequence analysis of the E2 region revealed a nucleotide substitution that encodes a serine instead of a proline in the relevant amino acid sequence (TAVSP/STTLR) (Accession number FJ790771).

\section{Clinical features of UK2000/7.1 and CRB/93 infection}

Upon inoculation with the UK2000/7.1 strain, two of the animals displayed clinical signs from 7-8 days post inoculation (dpi). The disease then progressed and these two animals were euthanized 13 dpi when their clinical scores were above 15 (Fig 1A). Onset of clinical signs was delayed slightly in the remaining four inoculated animals with scores above 4 occurring at $14 \mathrm{dpi}$, after which they steadily increased until $17-18$ dpi when the animals were euthanized. The three in-contact animals had initial clinical signs at $16 \mathrm{dpi}$; the 
1 clinical scores were of a similar, but delayed, profile relative to the inoculated

2 animals. The biochip temperatures correlated well with the clinical scores (Fig

3 1C). The most prominent clinical signs were a reddening of the conjunctiva

4 and soft faeces or diarrhoea. These early signs were followed by loss of

5 appetite, lethargy, stiffness of gait and preputial oedema. Notably, no

6 reddening, haemorrhaghes or petechiae of the skin were observed in animals

7 infected with UK2000/7.1 during the duration of the experiment, apart from a

8 diffuse purplish discolouration of the abdominal skin of one of the pigs 9 euthanized on $13 \mathrm{dpi}$.

10 In pigs inoculated with the CBR/93 strain, clinical signs were delayed and less

11 severe (Fig 1B). Only one animal had signs resulting in a score above 5

12 before $15 \mathrm{dpi}$. The disease then progressed rapidly with two of the animals

13 dying unexpectedly overnight on 18 and 19 dpi and three of the remaining

14 four inoculated animals were euthanized at that point. One pig developed few

15 signs and appeared to be recovering from infection towards the end of the

16 experiment on day 20. Two of the in-contact animals developed mild clinical

17 signs from dpi 18. In addition to the less severe and delayed signs, it was

18 notable that CBR/93 inoculated animals had only a mild, rather insignificant

19 increase in temperature from 14 dpi (Fig 1D). Diarrhoea was again a

20 predominant sign as was lack of attentiveness. With this strain however, we

21 observed a reddening of the skin, particularly of the ears, but very little

22 conjunctivitis.

$24 \quad$ Viraemia and nasal shedding 
1 In both experiments viral RNA was detected in EDTA blood of all but one of

2 the inoculated animals by $4 \mathrm{dpi}$, with the viral load increasing to a peak at 11

3 dpi (Figure 2A, B). One of the UK2000/7.1 inoculated animals, which

4 developed early clinical signs, was viraemic by 2 dpi and had a higher viral

5 RNA load than the other UK2000/7.1 inoculated animals. On average the

6 viral RNA copy number in blood was $1 \log _{10}$ lower in CBR/93 than UK2000/7.1

7 inoculated animals between dpi 6 and 11. The pig that developed few clinical

8 signs, following inoculation with $C B R / 93$, became viraemic at the same time

9 as the other CBR/93 inoculated animals, but the viral RNA load did not reach

10 the same level and started to decrease from $11 \mathrm{dpi}$. In the case of both

11 strains, the in-contact animals became viraemic at $14 \mathrm{dpi}$, 3-4 days before

12 clinical signs developed (Fig 2A, B).

13 Viral RNA was detected in nasal swabs from all inoculated animals between 5

14 and 8 dpi; 2-3 days after the animals became viraemic, but before the onset of

15 clinical signs (Fig2A, B). Viral RNA in nasal swabs then increased before

16 reaching a plateau at $14 \mathrm{dpi}$. The viral load in nasal swabs of CBR/93

17 inoculated-animals was lower than with UK2000/7.1. Interestingly, low levels

18 of viral RNA were present in the nasal swabs of the in-contact animals shortly

19 after the inoculated animals started shedding, but before these in-contacts

20 became viraemic. This low level persisted, then increased 2 days after the

21 animals became viraemic.

23 Haematology

24 Animals, inoculated with either virus, developed thrombocytopenia (Fig 2C,

25 D). Platelet counts decreased below the levels in uninfected control animals 
1 from 6 dpi for UK2000/7.1 inoculated animals, whereas a difference between

2 inoculated and control animals was only observed after $11 \mathrm{dpi}$ for CBR/93

3 inoculated animals, when the reduction in platelets was then more severe.

4 Animals also developed leukopenia (Fig 2E,F) with leukocyte counts

5 decreasing below levels in control animals from $4 \mathrm{dpi}$.

6

7 Pathology

8 Animals inoculated with UK2000/7.1 and CBR/93 isolates had a generalized

9 bilateral lymphadenopathy. The mandibular, lateral and medial

10 retropharyngeal lymph nodes were most affected (Supplemental Figures S1,

11 S2), followed by prescapular and ventral cervical superficial and, to a lesser

12 extent, precrural, ileocaecal and inguinal superficial lymph nodes. Other

13 frequently observed lesions were hydrothorax, hydropericardium, ascitis,

14 secondary bacterial bronchopneumonia and presence of necrotic foci and

15 diphteroid plaques in the ileocaecal valve and colon. Splenic infarcts and

16 petechia in different organs were only observed on very few occasions. The

17 in-contact animals had similar, but less severe lesions, than inoculated

18 animals. Only minimal background lesions were found in control animals.

19 The most common histopathological finding observed in animals inoculated

20 with UK2000/7.1 and CBR/93 strains was a mild to severe lymphoid depletion

21 in the lymph nodes accompanied by hyperemia and haemorrhages. Different

22 degrees of lymphoid depletion were also observed in thymus and spleen.

23 Inflammatory lymphohistiocytic infiltrates were frequently observed as

24 perivascular cuffing in the liver, kidney and encephalon. In the ileocaceal

25 valve and colon, the findings consisted of ulcerative necrotizing colitis with 
1 fibrin deposition. The most commonly observed lung lesions were acute

2 bacterial bronchopneumonia and alveolar and interstitial oedema. The

3 uninfected control animals did not show significant changes.

4 When the results of each group were compared using the macro and

5 histopathological scoring systems no statistical differences were found

6 between UK2000/7.1 and CBR/93 inoculated or UK2000/7.1 and CBR/93 in-

7 contact animals. Significant differences were observed between the 3 groups

8 (inoculated, in-contact and control) within the same experiment $(P<0.05)$

9 (Figure 3).

\section{Discussion}

12 The clinical signs and outcomes of CSFV infections vary considerably

13 depending on inherent properties of the virus strain as well as host and

14 environmental factors. It is acknowledged that classifying the spectrum of 15 different strains of CSFV into categories of high, moderate or low virulence is 16 difficult. A system for assigning virulence based on the clinical score (CS >15

17 and temp $>41^{\circ} \mathrm{C}$ as a highly virulent strain, and CS of 5 to 15 as moderately

18 virulent) has been suggested (Mittelholzer et al., 2000) and is used by many 19 laboratories. The system is useful to provide comparability between 20 experiments. It is, however, difficult to assign the two strains used in this study 21 according to the parameters of this system. Although two of the animals 22 inoculated with UK2000/7.1 reached scores $>15$ by $13 \mathrm{dpi}$, the remaining 23 inoculated or in-contact animals were euthanized before reaching a clinical 24 score of 15 for welfare reasons. However, although these remaining animals 25 may have progressed to reach scores above 15 , the course of the disease 
1 was certainly delayed compared to the outcomes described upon infection

2 with strains generally considered as highly virulent such as Brescia, Eystrup

3 (Mittelholzer et al., 2000) and ISS/60 (Belak et al., 2008). The disease seen

4 with the UK2000/7.1 isolate more closely resembled the course of infection

5 observed with recent 2.1 and 2.3 isolates (Floegel-Niesmann et al., 2003).

6 Classification of UK2000/7.1 as a moderately virulent strain is therefore

7 appropriate and is consistent with anecdotal observations in the field during

8 the 2000 outbreak that the strain appeared less virulent than historic isolates.

9 Assessment of the clinical signs caused by CBR/93 in the first 2 weeks would

10 result in the strain being described as having low virulence. However the rapid

11 progression of disease at $17 \mathrm{dpi}$, resulting in unexpected death of two

12 animals, and a similar degree of pathology at post mortem compared to

13 UK2000/7.1 categorizes this virus in the moderately virulent group.

14 Importantly, these observations highlight the difficulty in the clinical diagnosis

15 of CSF. In particular clinical signs such as high fever and skin lesions

16 classically associated with the disease may not be present in these early

17 stages.

18 Although clinical signs were not obvious, high levels of viral RNA were easily

19 detected in both blood and nasal swabs during these early stages of infection.

20 Advances in real time RT- PCR and automation of RNA extraction in the last

21 few years open up more possibilities for large-scale and rapid laboratory

22 testing for viral nucleic acid. It would therefore be beneficial if samples were

23 submitted early for laboratory tests, if only to exclude the possibility of CSFV

24 infection. 
1 The use of biochips for monitoring temperatures provided practical

2 advantages in terms of ease of monitoring which reduced disturbance of the

3 animals and allowed more frequent measurements. This highlighted the

4 importance of taking temperatures at consistent times as the animals had a

5 marked circadian rhythm. It is possible that hyperthermia would be more

6 apparent with the CBR/93 strain if rectal temperatures were monitored.

7 However separate assessment of biochip verses rectal temperatures over a

8 longer period indicate that, although the actual values are different, changes

9 in temperature monitored by the two methods correlate well (unpublished 10 data).

11 Despite the differences observed in the clinical signs, infection with both 12 isolates resulted in similar pathological scores. The in-contact animals 13 exposed to both strains were less affected pathologically. This is likely due to 14 a delay in the initial infection although the different dose of infection is also 15 likely to have some effect on the course of disease. The most prominent 16 lesion observed was a generalized lymphadenopathy. Other lesions, such as 17 pinpoint haemorrhages in the kidney or splenic infarcts in the spleen, which 18 are sometimes considered to be pathognomonic of CSF, were observed on 19 only very few occasions. Similar lesions to those observed can be found in 20 animals with PDNS and virulent PRRS, again highlighting the need for early 21 considerations of laboratory testing.

22 Comparing the virological and haematological parameters many were slightly, 23 although not dramatically, lower and delayed with CBR/93 in comparison with 24 UK2000/7.1. Leukopenia and thrombocytopenia were delayed and the level 25 of viral RNA was lower in the blood during the second week post infection. 
1 These observations may be linked with the fewer and delayed clinical signs

2 observed with the CBR/93 strain. Preliminary data suggests that there is also

3 a difference in the infection of peripheral blood cells between the two viruses

4 (unpublished data) which may have implications for the clinical outcomes

5 observed. It is also interesting that the mutant virus T3v (Risatti et al., 2006),

6 in which a targeted change replaces the proline in the WH303 epitope, also

7 resulted in delayed clinical signs with reduced viraemia and shedding

8 compared to its' parental strain. This suggests that the delayed and less

9 severe clinical signs observed with CBR/93 may be a result of the changes in

10 the $\mathrm{WH} 303$ epitope rather than this being a feature of genotype 3.3 strains in

11 general. However, further studies would be needed with other genotype 3.3

12 strains to confirm this.

13 The $\mathrm{WH} 303$ epitope on the E2 protein is an immunodominant site, the 14 presence of which is widely utilised as part of the differential diagnosis of 15 CSFV (Zhang et al., 2006). The natural occurrence of CSFV that do not react 16 with this antibody should therefore be heeded during differential diagnosis and 17 highlights that results from procedures reliant on a single CSFV-specific 18 monoclonal antibody must be interpreted with caution. It also raises questions 19 concerning the efficacy of conventional vaccines against such strains.

20 One of the aims of this study was to establish relevant challenge models for

21 future vaccination and pathogenicity studies. The similarities of the clinical 22 outcome with UK2000/7.1 to other recent genotype 2 isolates and the 23 antigenic and genetic diversity represented by the CBR/93 isolate highlight 24 that these two strains represent relevant challenge models of current CSFV 25 isolates. Both viruses were consistently transmitted to in-contact animals, 
1 which will allow prevention of shedding by vaccination to be assessed. The

2 extended macro- and histopathological scoring systems described here will

3 allow systematic comparison and assessment of pathological findings related

4 to CSF infection.

5

6

$7 \quad$ References

8 Belak, K., Koenen, F., Vanderhallen, H., Mittelholzer, C., Feliziani, F., De Mia, 9 G.M., Belak, S., 2008, Comparative studies on the pathogenicity and tissue distribution of three virulence variants of classical swine fever virus, two field isolates and one vaccine strain, with special regard to immunohistochemical investigations. Acta Vet Scand 50, 34.

Drew, T.W., 2008, Classical Swine Fever (hog cholera), In: OIE Manual of Diagnostic Tests and Vaccines for Terrestrial Animals (mammals, birds and bees). . World Organisation for Animal Health (OIE), Paris, France, pp. 1092-1106.

Floegel-Niesmann, G., Bunzenthal, C., Fischer, S., Moennig, V., 2003, Virulence of recent and former classical swine fever virus isolates evaluated by their clinical and pathological signs. J Vet Med B Infect Dis Vet Public Health 50, 214-220.

Gibbens, J., Mansley, S., Thomas, G., Morris, H., Paton, D., Drew, T., Sandvik, T., Wilesmith, J., 2000, Origins of the CSF outbreak. Vet Rec $147,310$.

Greiser-Wilke, I., Fritzemeier, J., Koenen, F., Vanderhallen, H., Rutili, D., De Mia, G.M., Romero, L., Rosell, R., Sanchez-Vizcaino, J.M., San 
Gabriel, A., 2000, Molecular epidemiology of a large classical swine fever epidemic in the European Union in 1997-1998. Vet Microbiol 77, $17-27$.

Hoffmann, B., Beer, M., Schelp, C., Schirmeier, H., Depner, K., 2005, Validation of a real-time RT-PCR assay for sensitive and specific detection of classical swine fever. J Virol Methods 130, 36-44.

Lin, M., Lin, F., Mallory, M., Clavijo, A., 2000, Deletions of structural glycoprotein E2 of classical swine fever virus strain alfort/187 resolve a linear epitope of monoclonal antibody $\mathrm{WH} 303$ and the minimal $\mathrm{N}$ terminal domain essential for binding immunoglobulin $\mathrm{G}$ antibodies of a pig hyperimmune serum. J Virol 74, 11619-11625.

Mittelholzer, C., Moser, C., Tratschin, J.D., Hofmann, M.A., 2000, Analysis of classical swine fever virus replication kinetics allows differentiation of highly virulent from avirulent strains. Vet Microbiol 74, 293-308.

Murray, G., McCutcheon, S., 1999, Model framework and principles of emergency management. Rev Sci Tech 18, 15-20.

Parchariyanon, S., Damrongwatanapokin, S., Pinyochon, W., Inui, K., Blacksell, S., Sawada, T., 2001, Diverisity of classical swine fever virus in Thailand: antigenic and vaccine efficiency studies. J. Thai Vet. Med. Assoc. 52.

Parchariyanon, S., Inui, K., Damrongwatanapokin, S., Pinyochon, W., Lowings, P., Paton, D., 2000, Sequence analysis of E2 glycoprotein genes of classical swine fever viruses: identification of a novel genogroup in Thailand. Dtsch Tierarztl Wochenschr 107, 236-238. 
1 Paton, D., 2002, The reappearance of classical swine fever in England in 2000, In: Morilla, A., Yoon, K.-J., Zimmerman, J.J. (Eds.) Trends in emerging viral infections of swine. Iowa State Press, lowa, pp. 153158.

Risatti, G.R., Holinka, L.G., Carrillo, C., Kutish, G.F., Lu, Z., Tulman, E.R., Sainz, I.F., Borca, M.V., 2006, Identification of a novel virulence determinant within the E2 structural glycoprotein of classical swine fever virus. Virology 355, 94-101.

Sandvik, T., Crooke, H., Drew, T.W., Blome, S., Greiser-Wilke, I., Moennig, V., Gous, T.A., Gers, S., Kitching, J.A., Buhrmann, G., Bruckner, G.K., 2005, Classical swine fever in South Africa after 87 years' absence. Vet $\operatorname{Rec} 157,267$.

Sandvik, T., Drew, T., Paton, D., 2000, CSF virus in East Anglia: where from? Vet Rec 147, 251.

Terpstra, C., de Smit, A.J., 2000, The 1997/1998 epizootic of swine fever in the Netherlands: control strategies under a non-vaccination regimen. Vet Microbiol 77, 3-15.

Vilcek, S., Herring, A.J., Herring, J.A., Nettleton, P.F., Lowings, J.P., Paton, D.J., 1994, Pestiviruses isolated from pigs, cattle and sheep can be allocated into at least three genogroups using polymerase chain reaction and restriction endonuclease analysis. Arch Virol 136, 309323.

Zhang, F., Yu, M., Weiland, E., Morrissy, C., Zhang, N., Westbury, H., Wang, L.F., 2006, Characterization of epitopes for neutralizing monoclonal 
antibodies to classical swine fever virus E2 and Erns using phagedisplayed random peptide library. Arch Virol 151, 37-54.

3

\section{Acknowledgements}

5 We particularly thank Alison Ward, Nicola White and Mick Kirby for their

6 excellent assistance with the animals. The efforts of Ian Wright, Meenakshi

7 Khatri, Olubukola Sosan and JaeJo Kim, from the National Veterinary

8 Research and Quarantine Service, Republic of Korea, in the processing of

9 samples are also very much appreciated. This study was funded by DEFRA 10 project SE0778.

11

12

13 Conflicts of interest

14 None

15

16 
1 Table I.

2 Macropathology parameters for post mortem evaluation of pigs infected with Classical swine fever virus. Scores from 0 (no lesion) 3 to 3 (severe lesions).

\begin{tabular}{|c|c|c|c|}
\hline \multirow[t]{2}{*}{ Parameter } & \multicolumn{3}{|c|}{ Score } \\
\hline & $+(1)$ & $++(2)$ & $+++(3)$ \\
\hline Body condition & Fair & Poor & Emaciated/cachectic \\
\hline Skin and subcutis & Erythema & Hemorrhages in several places & Multiple generalized hemorrhages \\
\hline Tonsils & Hyperemia & Focal necrosis & Multifocal/generalized necrosis \\
\hline Fluid in body cavities & $\begin{array}{l}\text { Ascitis or hydrothorax or } \\
\text { hydropericardium }\end{array}$ & Fluid in 2 cavities & $\begin{array}{l}\text { Acsitis, hydrothorax and } \\
\text { hydropericardium }\end{array}$ \\
\hline Spleen & Enlargement/splenomegaly & Individual infarction & Multiple infarcts \\
\hline Kidney & Individual petechiae & Several petechia & Multiple petechia and discoloration \\
\hline Ileum and ICV & $\begin{array}{l}\text { Single serosal hemorrhages or } \\
\text { hyperemia }\end{array}$ & $\begin{array}{l}\text { Several hemorrhages and/or } \\
\text { necrosis }\end{array}$ & Multiple necrotic foci \\
\hline Caecum and colon & Hyperemia & Single necrotic foci & Multiple necrotic foci \\
\hline Brain and meninges & Mild hyperemia & Moderate hyperemia & Fibrinopurulent meningitis \\
\hline Respiratory system & Mild bronchitis/rhinitis & $\begin{array}{l}\text { Single lobe bronchopneumonia or } \\
\text { pleuritis }\end{array}$ & $\begin{array}{l}\text { Multiple lobes bronchopneumonia and } \\
\text { pleuritis }\end{array}$ \\
\hline & $\begin{array}{l}\text { Mild enlargement and/or } \\
\text { hyperemia/petechiae }\end{array}$ & $\begin{array}{l}\text { Moderate enlargement and } \\
\text { hyperemia/petechiae }\end{array}$ & $\begin{array}{l}\text { Severe enlargement and } \\
\text { hyperemia/petechia }\end{array}$ \\
\hline Unrinary bladder & Single petechiae & Multiple hemorrhages & Confluent ecchimotic haemorrhages \\
\hline Thymus & Mild atrophy & Moderate atrophy & Severe atrophy \\
\hline Conjunctiva & Mild serous conjunctivitis & Moderate seropurulent conjunctivitis & Severe purulent conjunctivitis \\
\hline
\end{tabular}

*Lymph nodes: precrural, inguinal superficial, mandibular, lateral retropharyngeal, medial retropharyngeal, prescapular, ventral cervical superficial and ileocaecal.

ICV = ileocaecal valve 
Table II.

Histopathology parameters for evaluation of pigs infected with Classical swine fever virus. Scores applied for each lesion are: 0, no lesion; 1, mild; 2,

moderate; 3 , severe

5

6

\begin{tabular}{|c|c|}
\hline Tissue & Parameters scored \\
\hline Tonsils & $\begin{array}{l}\text { Lymphoid depletion } \\
\text { Hyperemia/hemorrhages }\end{array}$ \\
\hline Spleen & $\begin{array}{l}\text { Lymphoid depletion } \\
\text { Hemorrhages }\end{array}$ \\
\hline Thymus & Lymphoid depletion \\
\hline Lymph nodes* & $\begin{array}{l}\text { Lymphoid depletion } \\
\text { Hemorrhages/hyperemia }\end{array}$ \\
\hline Liver & $\begin{array}{l}\text { Periportal lymphplasmacytic } \\
\text { infiltrates }\end{array}$ \\
\hline Lung & $\begin{array}{l}\text { Alveolar/septal edema } \\
\text { Acute Bronchopneumonia }\end{array}$ \\
\hline Kidney & $\begin{array}{l}\text { Hyperemia/hemorrhages } \\
\text { Inflammatory infiltrates }\end{array}$ \\
\hline Encephalon & $\begin{array}{l}\text { Perivascular cuffing } \\
\text { Meningitis }\end{array}$ \\
\hline Ileocaecal valve & $\begin{array}{l}\text { Lymphoid depletion } \\
\text { Ulceration/Necrosis }\end{array}$ \\
\hline Colon & $\begin{array}{l}\text { Lymphoid depletion } \\
\text { Ulceration/Necrosis }\end{array}$ \\
\hline Bone marrow & Hypocellularity \\
\hline
\end{tabular}

$9 \quad$ *Lymph nodes: precrural, inguinal superficial, mandibular, lateral

10 retropharyngeal, medial retropharyngeal, prescapular, ventral cervical

11 superficial and ileocaecal.

12 
1

2

3

4

\section{Figure legends}

\section{Fig 1}

Clinical scores and temperatures following experimental infection with UK2000/7.1 and CBR/93 viruses.

Mean clinical scores of inoculated, in-contact, and controls of animals following infection with UK2000/7.1 (A) and CBR/93 (B). For UK2000/7.1 two groups of inoculated animals, which displayed different kinetics in the onset of clinical signs, are plotted separately. Note that due to the low clinical scores observed upon CBR/93 infection results are plotted on a different scale. Mean biochip temperatures of inoculated, in-contacts or control animals following infection with UK2000/7.1 (C) or CBR/93 (D), error bars represent SEM.

\section{Fig 2}

Virological and haematological parameters following experimental infection with UK2000/7.1 and CBR/93 viruses.

Viraemia and nasal shedding of animals infected with UK2000/7.1 (A) and CBR/93 (B). The mean copy number of viral genome per $\mu$ l of EDTA blood or nasal swab suspension in inoculated and in-contact animals as determined by qRT-PCR. Data for the CRB/93 inoculated animal that showed few clinical signs are excluded. Mean platelet counts, determined by flow cytometry, in animals inoculated with the UK2000/7.1 (C) and CBR/93 (D) viruses and compared to two uninfected control animals. Leukocyte counts were similarly monitored in the inoculated and control animals in the UK2000/7.1 (E) and CBR/93 (F) experiments by determining the mean total leucocyte count per $\mu$ l. Results are the mean data for each group of pigs. Error bars represent SEM. 
2

$3 \quad$ Fig 3

4 Macropathology (A, B) and histopathology (C, D) scores following

5 experimental infection with UK2000/7.1 (A, C) and CBR/93 (B, D). Boxes

6 represents percentile 25 to 75; whiskers represents maximum and minimum

7 values; lines represent medians.

8 


\section{Supplemental Figure legends}

\section{Figure S1}

3 Examples of macropathology and histopathology scoring, following

4 experimental infection with CSFV UK2000/7.1 (A, B, C) and CBR/93 (D, E, F).

5 A Haemorrhagic lymphadenitis in lateral retropharyngeal lymph node (score

$6 \quad 3$ ); B Button ulcers in the ileacaecal valve and colon (score 3); C Perivascular

7 cuffings in the brainstem (score 3). Original magnification 100x; D Petechial

8 and ecchymotic haemorrhages in the subcutaneous tissue (score 3); E Areas

9 of bronchopneumonia in the apical lung lobes (score 3); F Severe thymic

10 atrophy with loss of lymphocytes and no separation between cortex and

11 medulla (score 3). Original magnification: 100x.

\section{$12 \quad$ Figure $\mathbf{S 2}$}

13 Examples of scoring of macropathological and histopathological changes

14 following experimental infection with $\mathrm{CBR} / 93$ in lateral retropharyngeal lymph

15 nodes from inoculated $(A, D)$, in-contact $(B, E)$ and uninfected controls $(C, F)$.

16 A. Severe enlargement and hyperemia (score 3); B. Moderate enlargement

17 and hyperemia (score 2). C. Normal (score 0). D. Severe haemorrhages and

18 hyperemia (score 3) and moderate lymphoid depletion (score 2); E. Mild

19 haemorrhages and hyperemia (score 1) and moderate lymphoid depletion

20 (score 2); F. No hyperemia/haemorrhages (score 0) and no lymphoid

21 depletion (score 0). 


\section{Fig 1}

A

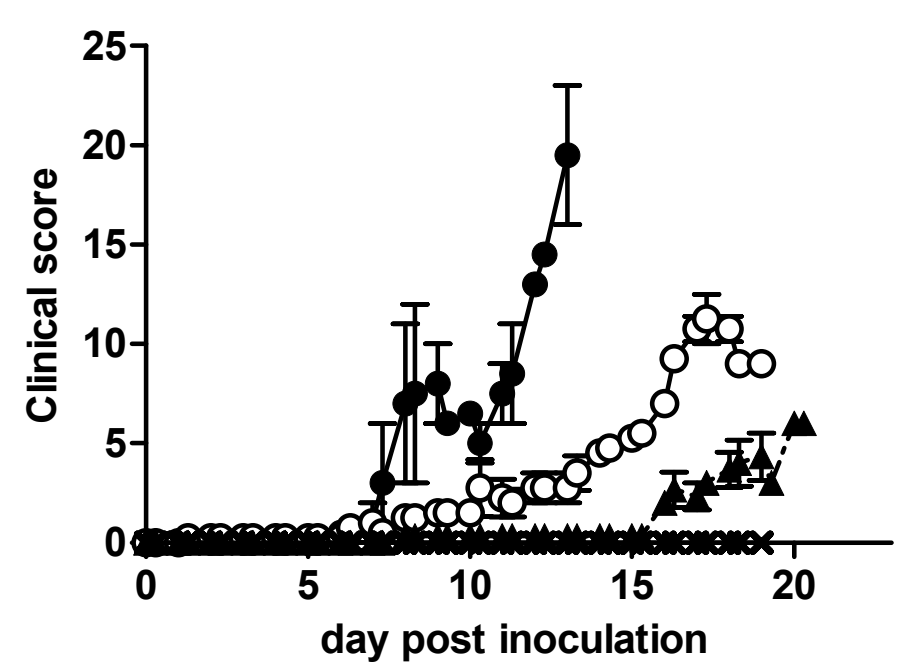

C

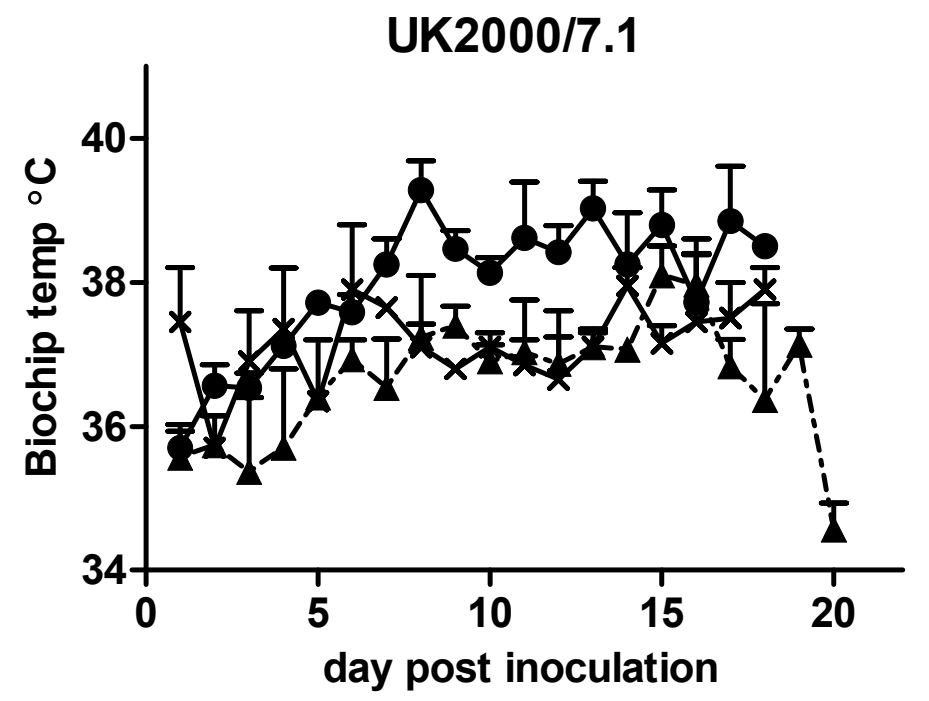

B

- Inoculated $(\mathrm{n}=2)$

-o- Inoculated $(n=4)$

-A. In contacts

* Controls

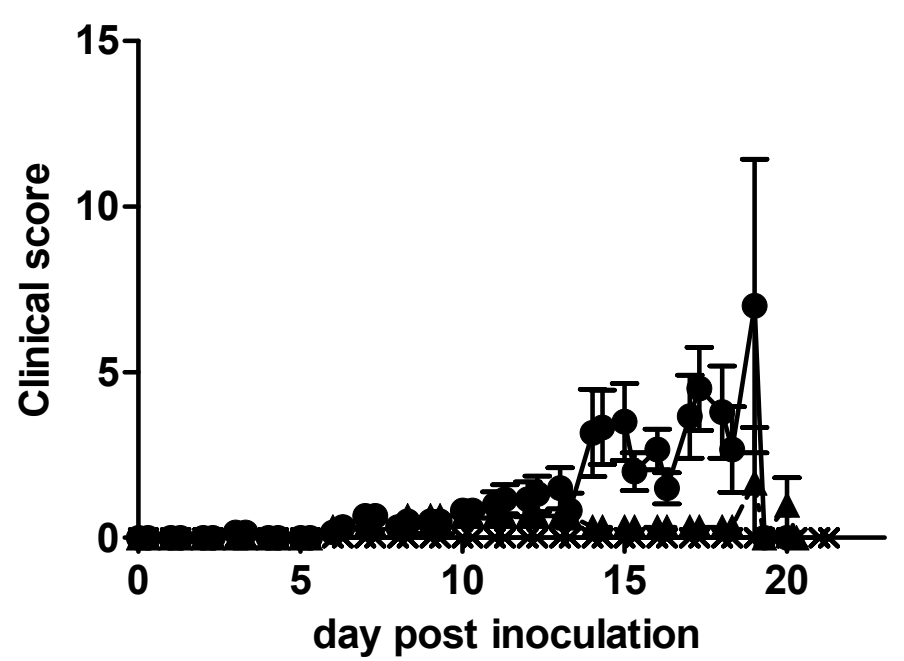

D

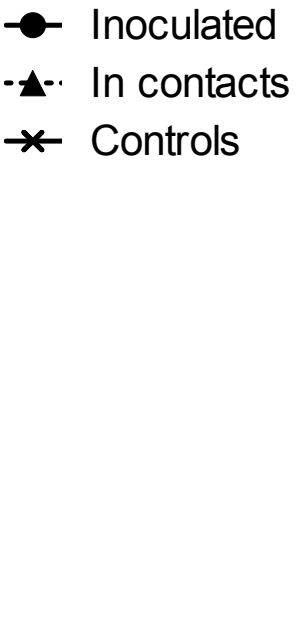

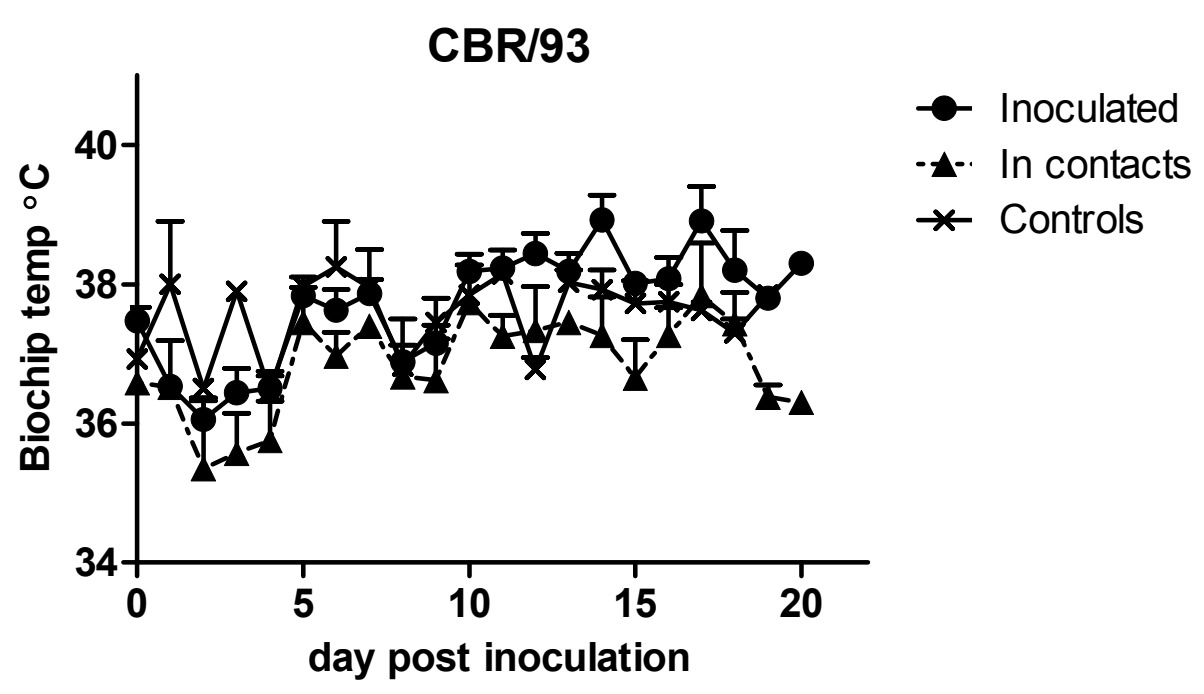


Fig 2

\section{UK2000/7.1}

A

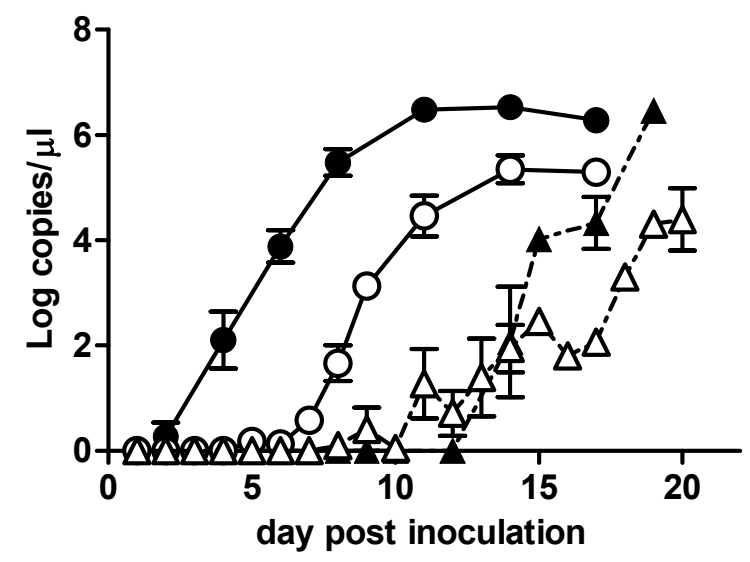

C

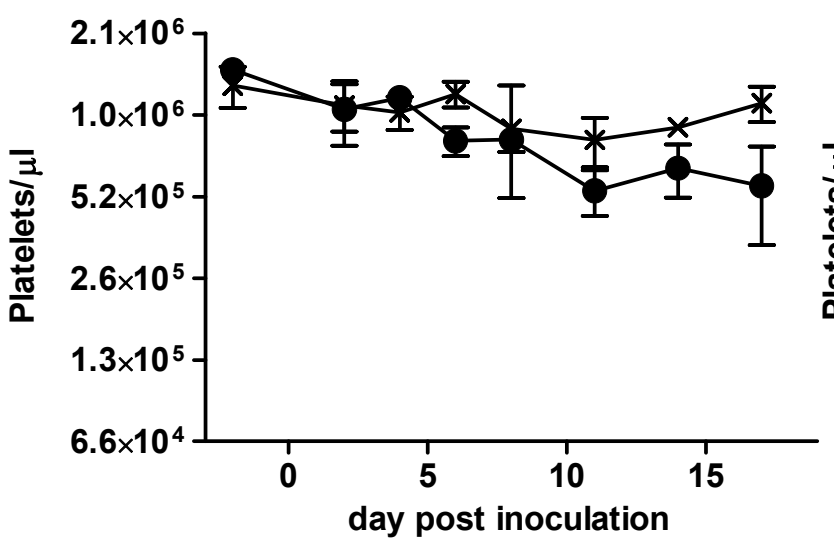

E

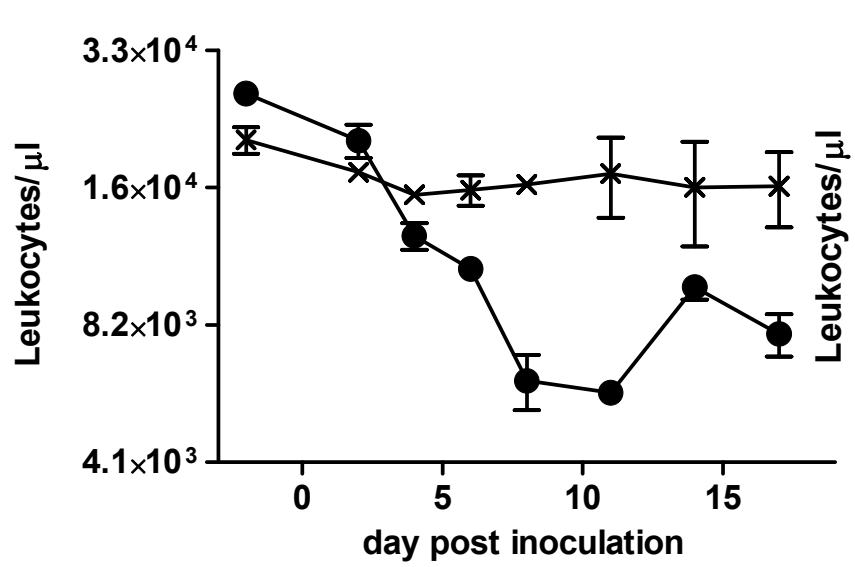

\section{CBR/93}

B

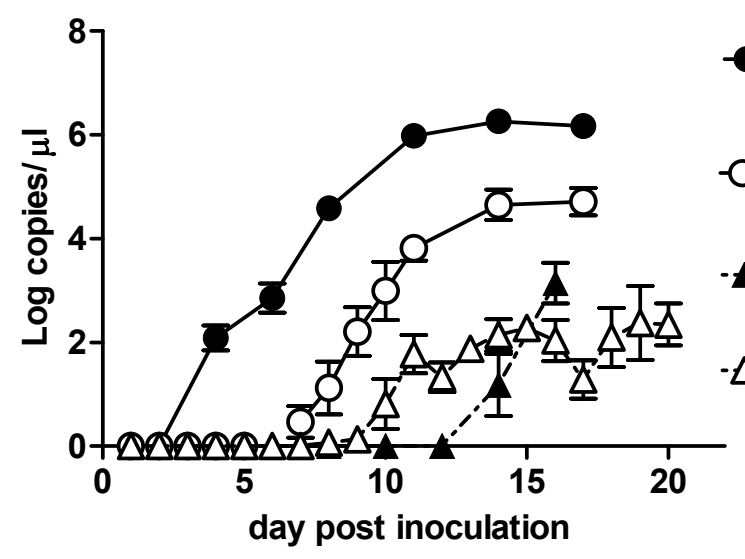

Inoculated

- Viraemia

-O- Inoculated

- Shedding

In contacts

- Viraemia

$\triangle$ - In contacts

- Shedding

\section{D}

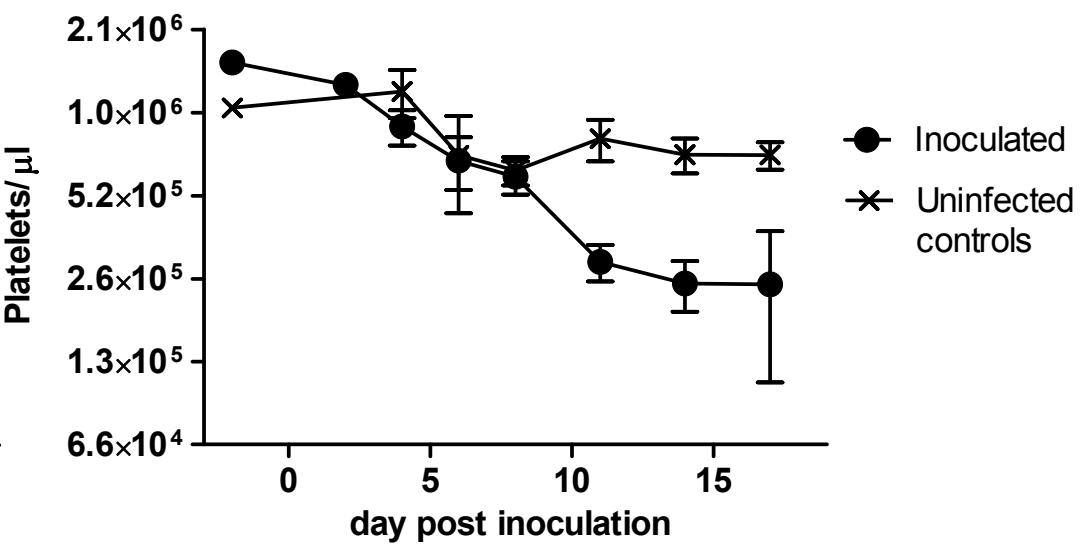

F

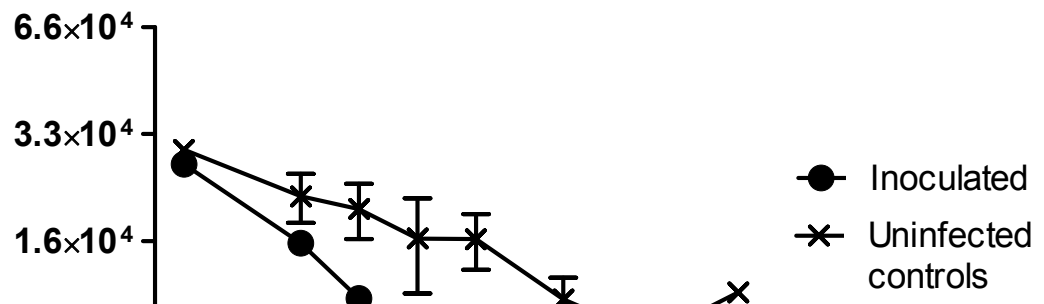

$4.1 \times 10^{3}$

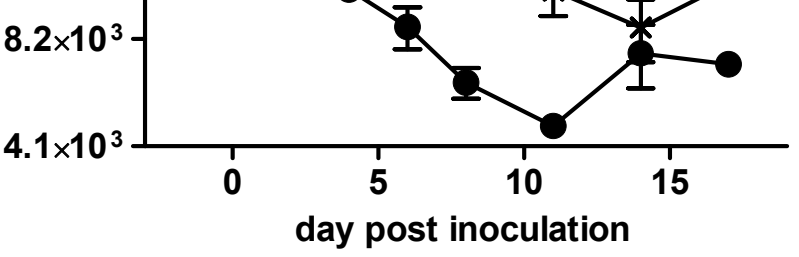
controls 
Fig 3
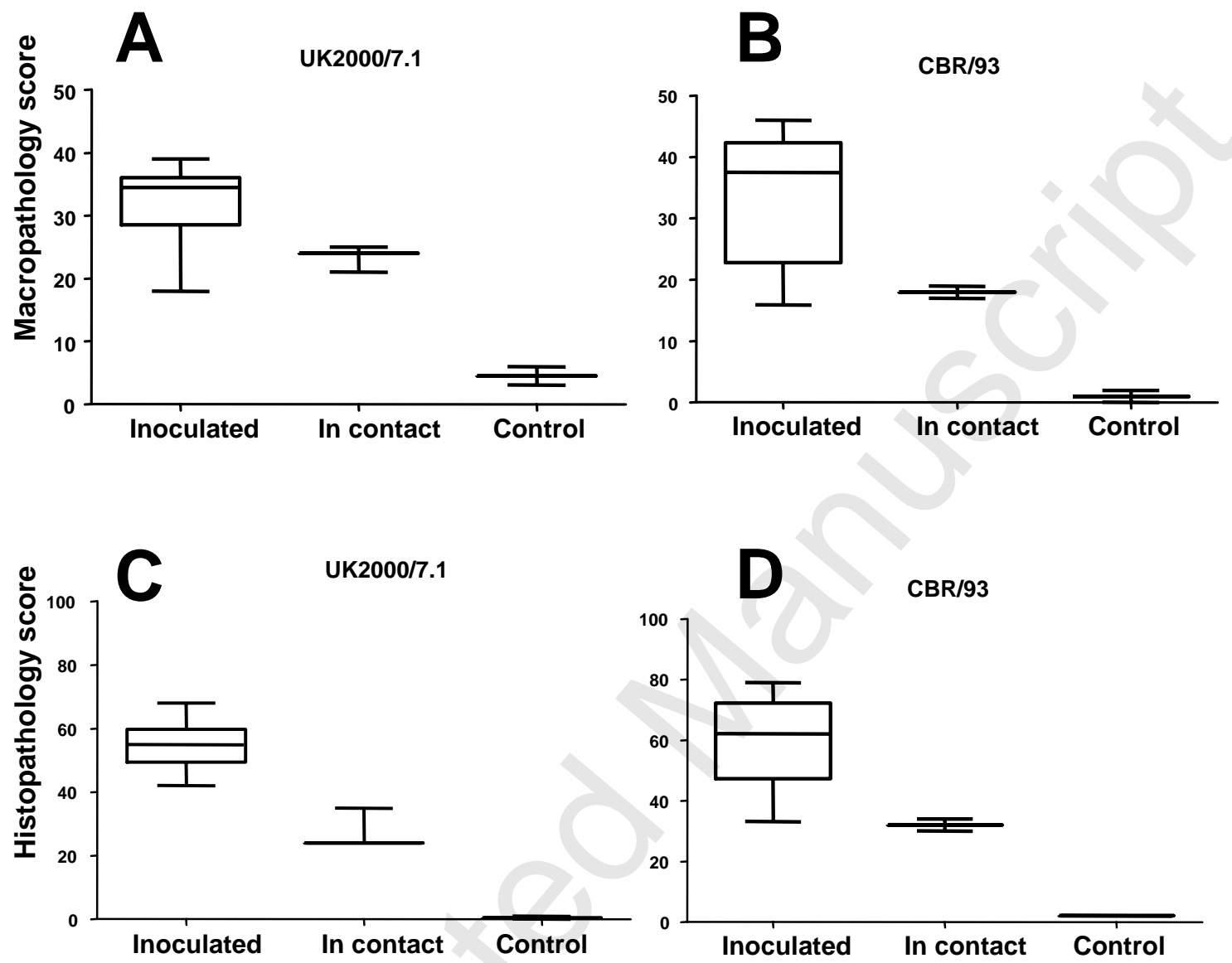